\title{
Experimental Investigation of Pressure Fluctuation, Vibration, and Noise in a Multistage Pump
}

\author{
Kai Wang $\mathbb{D}^{1},{ }^{1}$ Zixu Zhang $\mathbb{D}^{1},{ }^{1}$ Chen Xia $\mathbb{D}^{2},{ }^{2}$ and Zhongchun Liu $\mathbb{D}^{3}$ \\ ${ }^{1}$ Research Center of Fluid Machinery Engineering and Technology, Jiangsu University, Zhenjiang 212013, China \\ ${ }^{2}$ SAIC MAXUS Automotive Co., Ltd., Wuxi Branch, Wuxi 214000, China \\ ${ }^{3}$ Jiangsu Changjiang Water Pumps Co., Ltd., Kunshan 215300, China
}

Correspondence should be addressed to Kai Wang; wangkai@ujs.edu.cn

Received 21 August 2017; Accepted 1 February 2018; Published 4 March 2018

Academic Editor: Tai Thai

Copyright (C) 2018 Kai Wang et al. This is an open access article distributed under the Creative Commons Attribution License, which permits unrestricted use, distribution, and reproduction in any medium, provided the original work is properly cited.

\begin{abstract}
In order to measure the pressure pulsation, vibration, and noise characteristics of multistage centrifugal pump in different flow rates, a five-stage centrifugal pump was chosen as research object. The results show that the main frequency of pressure pulsation was $\mathrm{BPF}_{1}, 9 \mathrm{APF}, \mathrm{BPF}_{2}, \mathrm{BPF}_{2}$, and $9 \mathrm{APF}$. According to the order of monitoring points, the intensity of the pressure fluctuation increased and then decreased, with the strongest fluctuation at monitoring point $\mathrm{P} 2$. The peak value of pressure fluctuation in monitoring point $\mathrm{P} 2$ was obviously higher than the other monitoring points. The main characteristic frequency of vibration is $4 \mathrm{APF} \mathrm{BPF}_{2}$, $9 \mathrm{APF}, 2 \mathrm{BPF}_{2}, 3 \mathrm{BPF}_{1}, 4 \mathrm{BPF}_{1}$, and $4 \mathrm{BPF}_{2}$. The number of characteristic frequencies at the outlet flange was significantly more than the number of characteristic frequencies at the inlet flange. As the flow rate increased, the vibration of motor gradually increased and the vibration of pump increased at first and then decreased. It reached the minimum vibration level in the design flow rate. Motor contributed the largest amount of noise caused by the pump unit. The noise level of measure point which is close to motor is higher than that of other measure points. As the flow rate increased, the noise incrementally increased, and the difference in noise level between measure points decreased gradationally. When the flow rate was $120 \mathrm{~m}^{3} / \mathrm{h}$, the maximum difference value of different noise monitoring points was only $1.7 \mathrm{~dB}$.
\end{abstract}

\section{Introduction}

Multistage centrifugal pump has characteristics of high lift and large flow rate, which is widely used in electric power, fire, metallurgy, construction, and other fields. Due to the high rotation speed of the impeller and dynamic and static interference between impeller and volute or guide vane, the internal flow of the centrifugal pump is a kind of complex unsteady turbulence flow, which will cause pressure fluctuation inside the pump. The pressure fluctuation on the wall of pump will lead to the vibration and noise. Too large vibration will affect the reliability of pump operation. Therefore, measures should be taken to reduce the pressure fluctuation in the pump [1-6].

In recent years, scholars had conducted some research on the pressure fluctuation in the pump and obtained encouraging achievements. In the 1990s, the American FFPI company [7] found that the pressure fluctuation caused by the cavitation, along with the interaction of dynamic and static interference of blades, played an important role in the vibration of the centrifugal pump, which could also lead to the operation failure. Takahiro and Yusuke [8] simulated the pressure fluctuation in the centrifugal pump and found that the dominant frequency of the pressure fluctuation in the centrifugal pump was equal to the blade frequency. Spence and Amaral-Teixeira $[9,10]$ combined numerical simulation with experiment to study pressure fluctuation in the centrifugal pump. The influence of the change of geometric parameters on pressure fluctuation and pump performance was also analyzed. Majidi [11] simulated numerically the internal unsteady flow of centrifugal pump and studied the pressure fluctuation at the blade outlet. Kergourlay et al. [12] used numerical calculation and experimental measurement to research the flow field and pressure fluctuation in the centrifugal pump with splitter blade. It was found that the circumferential speed and pressure in the pump with splitter 
blade impeller become more uniform and the vibration and noise of the pump can be reduced. Dai et al. [13] studied the effect of impeller outlet width on the pressure fluctuation in pump chamber. It was found that the static pressure and the amplitude of pressure fluctuation in front pump chamber increased with the increase of outlet width and the decrease of radius. Liu et al. [14] detected the pressure fluctuation of the 3 monitoring points on the same circumference of the single channel inlet in each stage of the multistage pump and found that the pressure fluctuation of the first stage was the most severe and the pressure fluctuation decreased gradually with the increase of the stage number.

In the study of vibration and noise of centrifugal pump, Howe [15] pointed out that the coupling between the blades and the fluid vortices would indirectly cause the noise. When the vortex center moved close to the leading edge of the blade, the coupling effect would produce unsteady force on the blade, which caused the vibration of the blade and low frequency noise. Choi et al. [16] performed an experimental investigation on the unsteady flow field and noise generation mechanism for a centrifugal turbomachine by arranging of hot-wire detectors and surface mounted pressure transducers on the blades. Srivastav et al. [17] pointed out that the noise of centrifugal pump decreased with the increase of the gap between the impeller and the volute tongue. Dai et al. [18] measured the vibration and noise of pump as turbine at different rotation speed and flow rate. It was found that the level of vibration and noise increased with the increase of rotation speed and flow rate. The sound pressure level of outlet noise under the same flow rate was higher than that of the inlet. Sun et al. [19] and Zhou [20] studied the effect of off-design condition deviation on vibration and noise. Duan et al. [21] and Escaler et al. [22] measured and analyzed the vibration signal of centrifugal pump when the cavitation was happening. The experimental results show that the vibration acceleration level of vibration signal in some frequency ranges increased after cavitation.

However, the experimental studies about vibration and noise of centrifugal pump mainly focused on single-stage centrifugal pump. The studies on multistage centrifugal pump are relatively less. Therefore, the pressure fluctuation, vibration, and noise characteristics of a five-stage centrifugal pump with guide vane used in mine drainage in this paper under different flow rate are measured and analyzed to provide the basis for the subsequent CFD optimization and reduction of vibration and noise.

\section{Test Model and Arrangement of Monitoring Points}

The test equipment mainly consists of test pump, vacuum pump, submersible pump, flow meter, gate valve, and so on. The test instruments include 2 pressure transmitters, 2 pressure gauges, 1 photoelectric tachometer, 5 HY6503 type high frequency dynamic pressure transmitters, 4 INV 9832 type piezoelectric three-direction acceleration sensors, and 1 INV9206 sound pressure sensor. The INV vibration and noise testing system of Beijing Oriental vibration Institute is adopted as data acquisition system. The system contains
TABLE 1: Main structural parameters.

\begin{tabular}{lc}
\hline Main geometric parameters & Value \\
\hline Inlet diameter of inlet section $D_{1} / \mathrm{mm}$ & 100 \\
Impeller outer diameter $D_{2} / \mathrm{mm}$ & 314 \\
The number of first-stage impeller blades $Z_{1}$ & 6 \\
The outlet width of first-stage impeller $b_{2} / \mathrm{mm}$ & 20.5 \\
The number of second-stage impeller blades $Z_{2}$ & 7 \\
The outlet width of second-stage impeller $b_{3} / \mathrm{mm}$ & 20.5 \\
Inlet diameter of guide vane $D_{3} / \mathrm{mm}$ & 316 \\
Outer diameter of guide vane $D_{4} / \mathrm{mm}$ & 409 \\
Blade number of positive guide vane $Z_{3}$ & 9 \\
Blade number of negative guide vane $Z_{4}$ & 10 \\
Outlet diameter of outlet section $D_{5} / \mathrm{mm}$ & 80 \\
\hline
\end{tabular}

16 data acquisition channels and the maximum sampling frequency is $102.4 \mathrm{KHz}$.

2.1. Test Pump. The test pump is five-stage centrifugal pump. The blade number of the first-stage impeller is 6 and blade number of other-stage impeller is 7. The design flow rate $Q_{d}$ is $100 \mathrm{~m}^{3} / \mathrm{h}$, head $H$ is $165 \mathrm{~m}$, rotation speed $n$ is $1480 \mathrm{r} / \mathrm{min}$, and specific speed $n_{s}$ is 65.4 . Table 1 shows the main structural parameters of the five-stage centrifugal pump. Figure 1 is the five-stage centrifugal pump.

2.2. Energy Characteristic Test Results. The experimental results of the energy characteristics of the five-stage guidevane centrifugal pump are shown in Figure 2. As seen from Figure 2, under $0.8 Q_{d}$, the head is $172.9 \mathrm{~m}$, the power is $56.1 \mathrm{~kW}$, and the efficiency is $67.4 \%$. Under $1.0 Q_{d}$, the head is $165.4 \mathrm{~m}$, the power is $61.8 \mathrm{~kW}$, and the efficiency is $72.8 \%$. Under $1.2 Q_{d}$, the head is $152.3 \mathrm{~m}$, the power is $68.8 \mathrm{~kW}$, and the efficiency is $72.4 \%$. The highest efficiency point is located in $1.1 Q d$ and the efficiency is $74.06 \%$.

2.3. Arrangement of Pressure Fluctuation Monitoring Points. A total of 5 pressure fluctuation monitoring points are set to measure pressure fluctuation in the pump, as shown in Figure 3. The monitoring points $\mathrm{P} 1, \mathrm{P} 2, \mathrm{P} 3$, and $\mathrm{P} 4$ are located in the pressure port of the middle of the fourth stage. The monitoring point P5 is located in the outlet of the test pump. In the pressure fluctuation test, the sampling frequency of each monitoring point is $51.2 \mathrm{kHz}$ and the sampling time is $30 \mathrm{~s}$.

2.4. Arrangement of Vibration Monitoring Points. A total of 8 vibration monitoring points are set. The monitoring point $\mathrm{V} 1$ is located in bearing A near the pump outlet. The monitoring point V2 is located in bearing B near the coupling. The V3 and $\mathrm{V} 4$ are located at the inlet flange and the outlet flange of the pump. The V5 V8 are at the four pump foots. Figure 4 gives the location of monitoring points V2, V4, and V5. The installation mode of the sensor is magnetic seat installation. The horizontal, vertical, and axial vibration were measured at each monitoring point.

2.5. Arrangement of Noise Monitoring Points. A total of 8 monitoring points are set. The monitoring points M1, M2, 


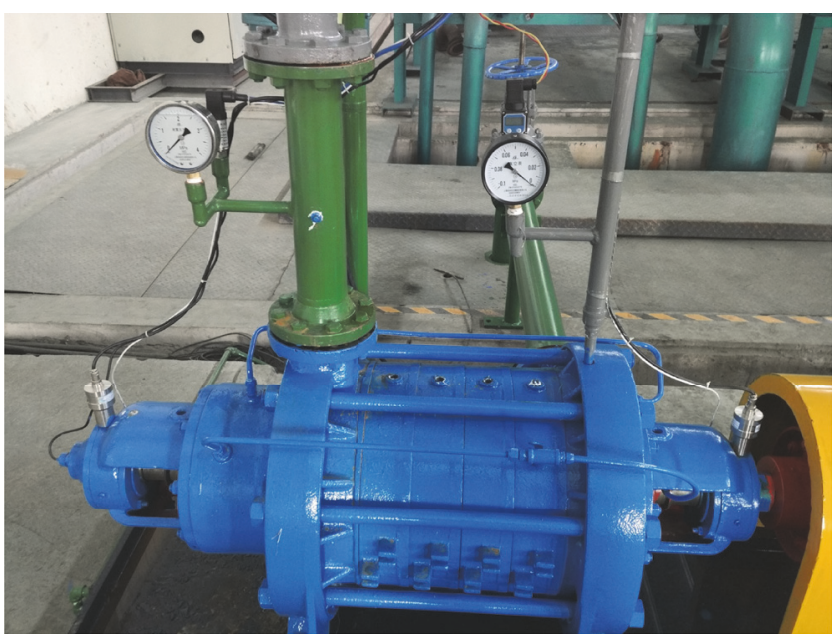

FIGURE 1: The test pump.

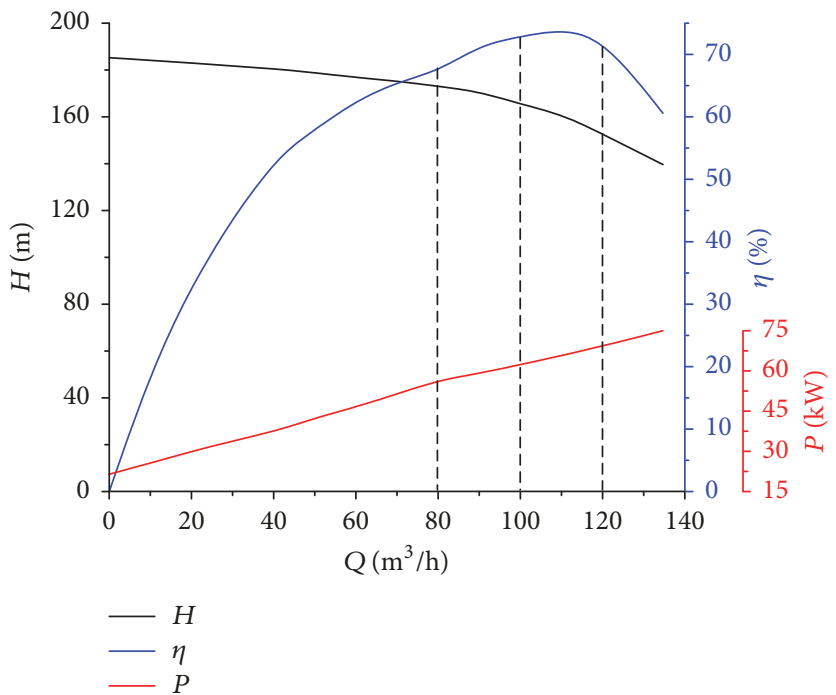

FIgURE 2: Experiment result of energy characteristics.

and M8 are located near the motor. The monitoring points M3 M7 are located near the pump. Each monitoring point is arranged at the distance of 1 meter from the test pump. The height from monitoring point to the base is also 1 meter. The positions of the points are shown in Figure 5.

\section{Test Results and Analysis of Pressure Fluctuation}

3.1. Pressure Fluctuation Data Processing Method. There are two methods to deal with the pressure fluctuation data. One is the time domain method, and the other is the frequency domain method. In this paper, the frequency domain method is adopted to deal with the test data.

Frequency domain method decomposes the complex signal of pressure fluctuation according to the frequency magnitude. Taking the frequency as the $X$ coordinate and the amplitude of pressure fluctuation as $Y$ coordinate, the energy distribution of the pressure fluctuation is presented on the spectrum. The most common method of frequency domain analysis is Fourier Transform. It transforms the time domain diagram into the frequency domain diagram and intuitively shows the frequency distribution of the pressure fluctuation. In this paper, the Fast Fourier Transform is used to analyze the frequency domain.

Assume that $X(n \Delta t)$ is a chronological sequence with length $M$. The calculation equation of discrete value $X_{m}(m=$ $0,1,2, \ldots, M-1)$ of spectrum $X(f)$ is

$$
X_{m}=X(m \Delta f)=\frac{1}{M} \sum_{n=0}^{M-1} x(n \Delta t) \exp \left(-j \frac{2 \pi n m}{M}\right),
$$

where $\Delta f$ is the frequency resolution, $M$ is the number of samples, and $\Delta t$ is the time step.

Define the blade frequency multiplier $N_{F}$ :

$$
N_{F}=\frac{60 F}{n}=\frac{F}{F_{n}},
$$




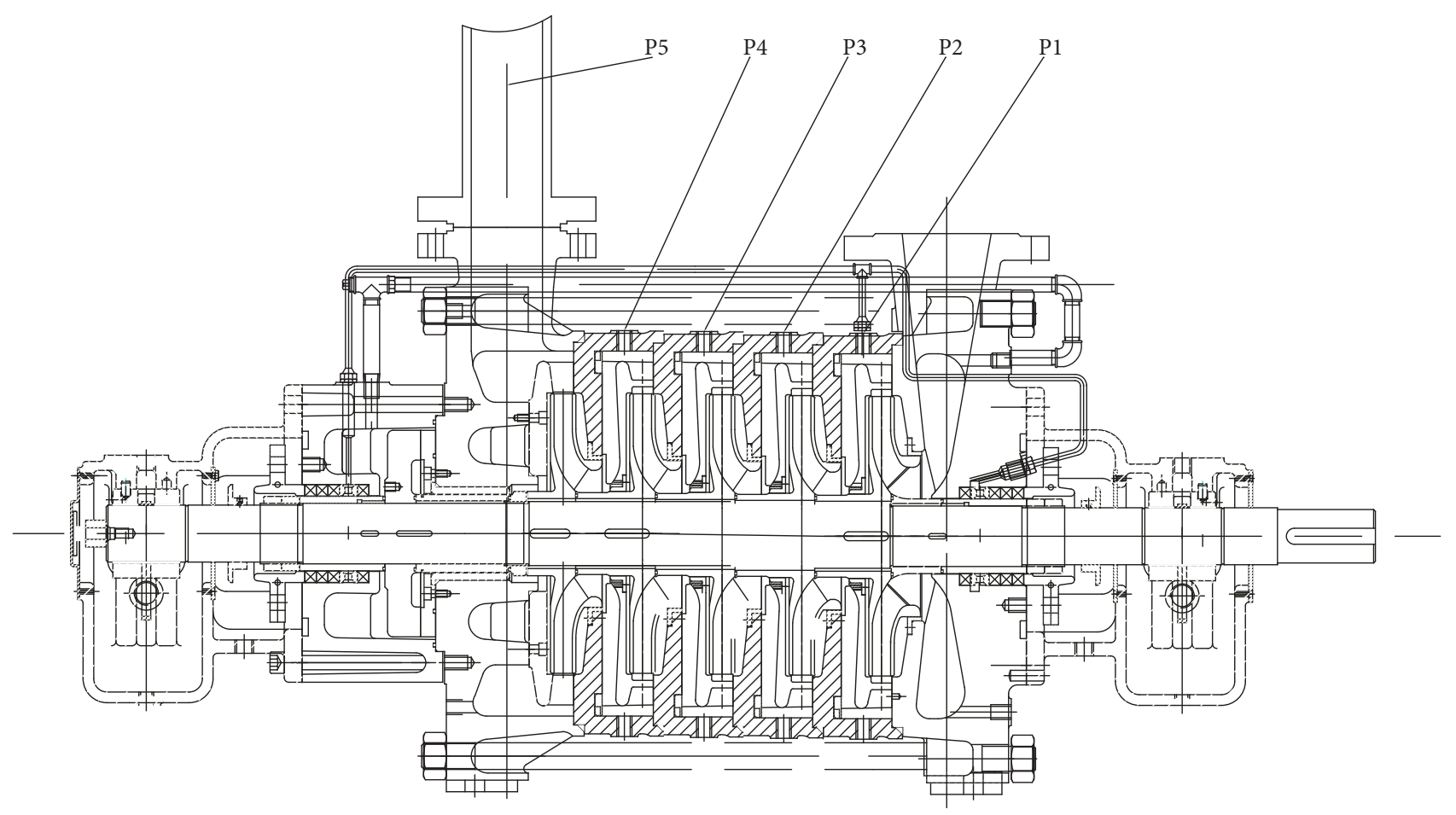

FIgURE 3: Location of the pressure fluctuation monitoring points.

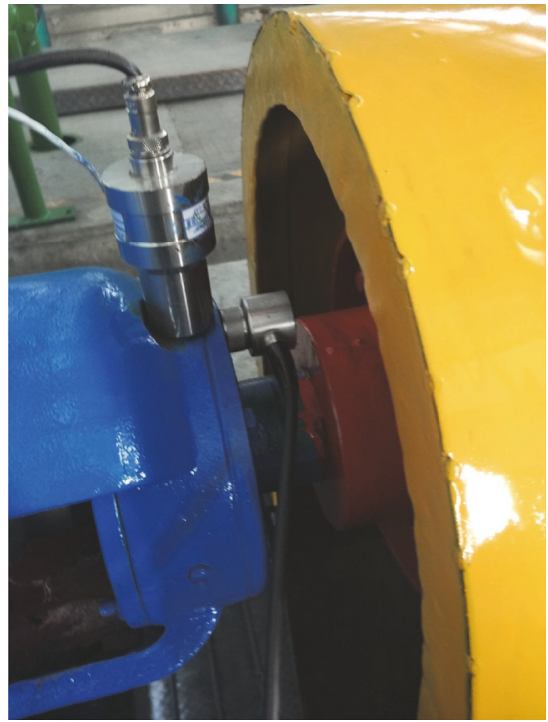

(a) V2

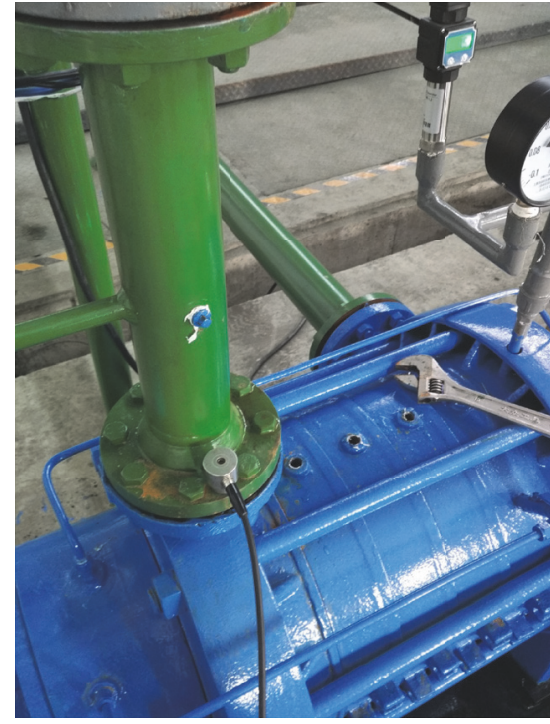

(b) V4

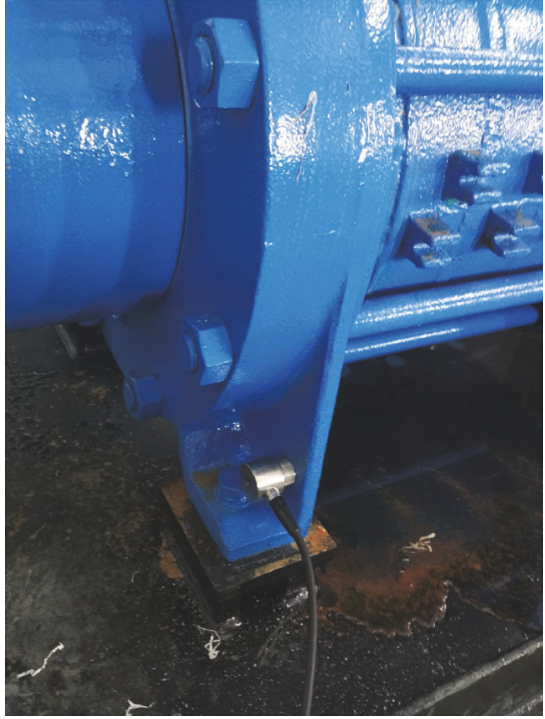

(c) V5

FIGURE 4: Location of vibration monitoring points.

where $F$ is the actual frequency after the Fourier Transform and $F_{n}$ is the pump shaft rotation frequency under corresponding rotation speed (APF).

\subsection{Pressure Fluctuation Characteristics under Design Flow} Rate. The pressure fluctuation frequency domains of the monitoring points $\mathrm{P} 1 \sim \mathrm{P} 5$ under the design flow rate are shown in Figure 6. The impeller rotation speed is $1480 \mathrm{r} / \mathrm{min}$.
The blade number of the first-stage impeller is 6 . The blade number of the second-stage impeller is 7. So the pump shaft rotation frequency (APF) is $24.67 \mathrm{~Hz}$. The frequency of the first-stage impeller blades passing through the guide vane $\left(\mathrm{BPF}_{1}\right)$ is $148 \mathrm{~Hz}$ and that of the second-stage impeller $\left(\mathrm{BPF}_{2}\right)$ is $172.67 \mathrm{~Hz}$. As can be seen from Figure 6, the dominant frequencies of $\mathrm{P} 1$ to $\mathrm{P} 5$ are $\mathrm{BPF}_{1}, 9 \mathrm{APF}, \mathrm{BPF}_{2}$, $\mathrm{BPF}_{2}$, and $9 \mathrm{APF}$. The corresponding peak values are $4.91 \mathrm{KPa}$, 


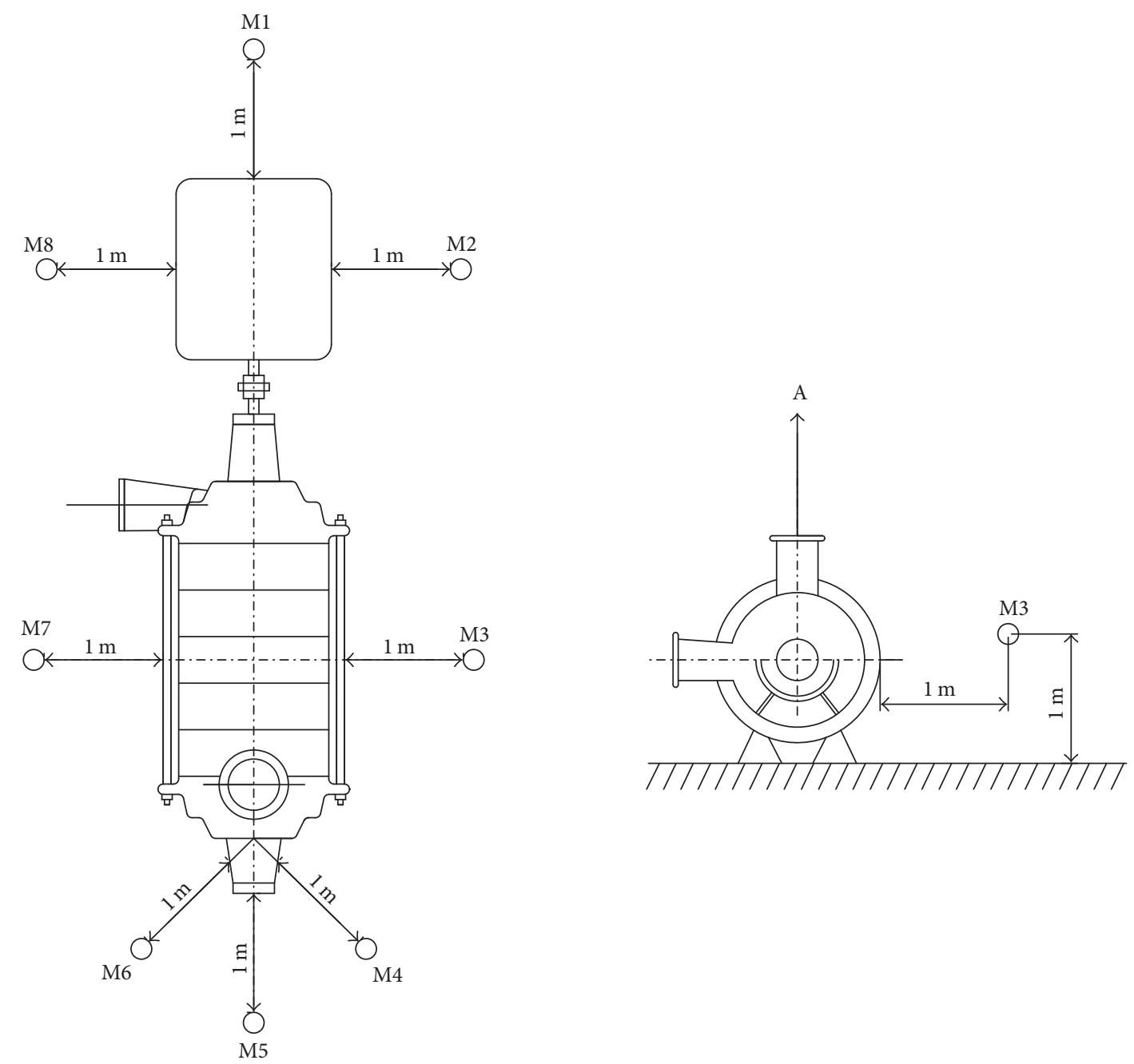

FIGURE 5: Location of noise monitoring points.

17.83 KPa, 13.75 KPa, 9.17 KPa, and 4.35 KPa. Comparing the pressure fluctuation of different stages, it can be found that the intensity of pressure fluctuation increases firstly and then decreases. From the second stage, the pressure fluctuation intensity gradually decreases with the increase of the stage number.

In addition to the dominant frequencies of each monitoring point $\left(\mathrm{BPF}_{1}, 9 \mathrm{APF}\right.$, and $\left.\mathrm{BPF}_{2}\right)$, the other obvious peak values are $\mathrm{APF}, 2 \mathrm{APF}, 3 \mathrm{APF}, 8 \mathrm{APF}$, and $10 \mathrm{APF}$. The frequency components of pressure fluctuation of each monitoring point are complex. However, the blade passing frequency can still be clearly seen and the fluctuation intensity is relatively larger. The blade frequency is attributed to the mutual interference between impeller and guide vane. The peak value of the shaft frequency is obviously less than the peak value of other characteristic frequencies. This is due to the relatively high manufacturing accuracy of the impeller.

\subsection{Pressure Fluctuation Characteristics of Each Monitoring} Point under Different Flow Rates. In order to further compare the pressure fluctuation characteristics under different flow rates, the pressure fluctuation frequency spectrums of the monitoring points P1 P5 under different flow rates are analyzed, as shown in Figure 7. As can be seen from Figure 7(a), the relatively obvious frequencies are APF, 2APF, and BPF1. The pressure fluctuation intensity under the offdesign flow rate is larger than that under the design flow rate. At the same time, the low frequency peak value of pressure fluctuation increases with the increase of flow rate. With the increase of flow rate, the characteristic blade frequency peak value of the monitoring point P1 increases firstly, then decreases, and reaches the maximum under the design flow rate.

The structure of the second-stage impeller to the fifthstage impeller is the same. As a result, the fluctuation trend of the monitoring points $\mathrm{P} 2 \sim \mathrm{P} 4$ is similar to the fluctuation frequency and the blade frequency is 7 times of the shaft frequency, as shown in Figures $7(\mathrm{~b})-7(\mathrm{~d})$. The obvious characteristic frequencies are 6APF, BPF, 9APF, 10APF, and 18.15APF. The 6 times shaft frequency is generated by firststage impeller. The peak value of $6 \mathrm{APF}$ decreases with the increase of the stages number. In the frequency spectrum of the monitoring point $\mathrm{P} 2$, the dominant frequencies under different flow rate are all the blade frequency. The peak value 


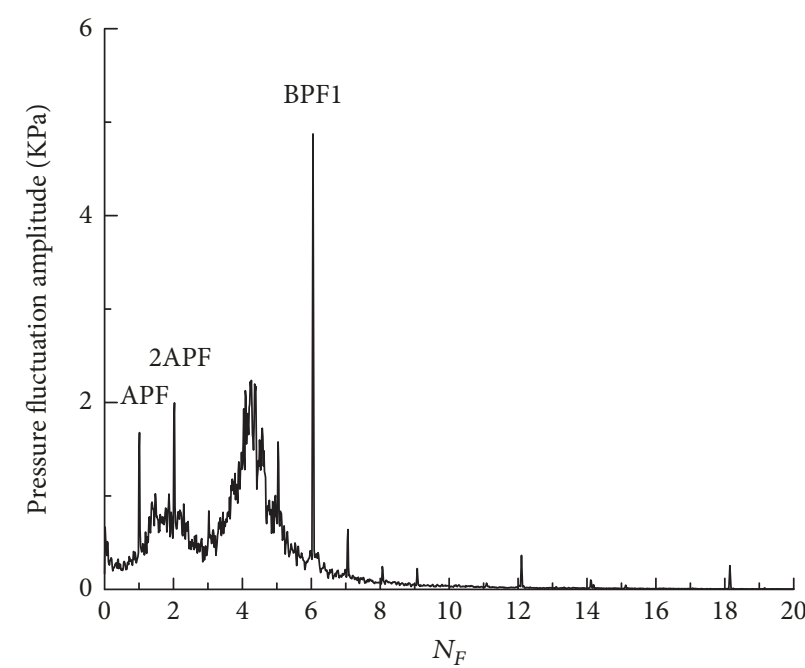

(a) $\mathrm{P} 1$

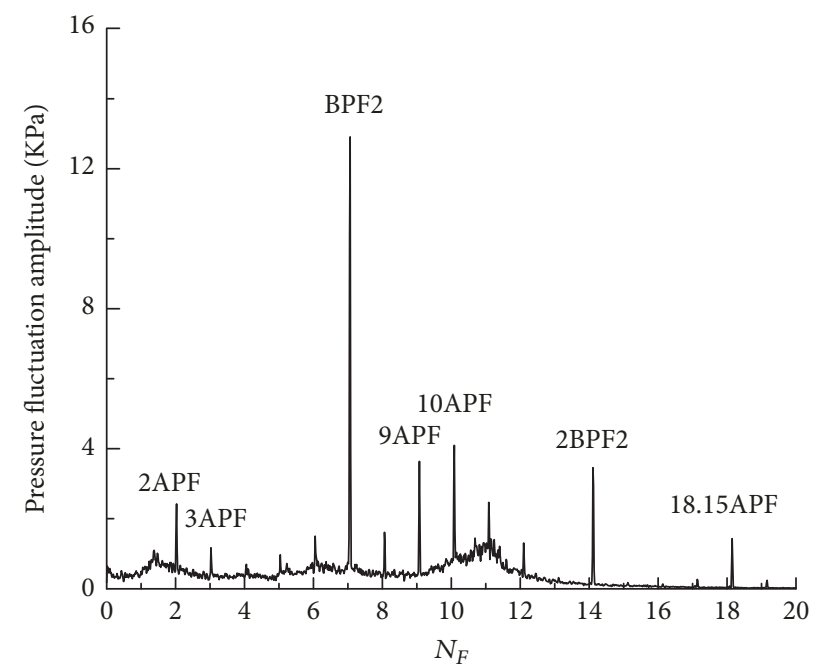

(c) $\mathrm{P} 3$

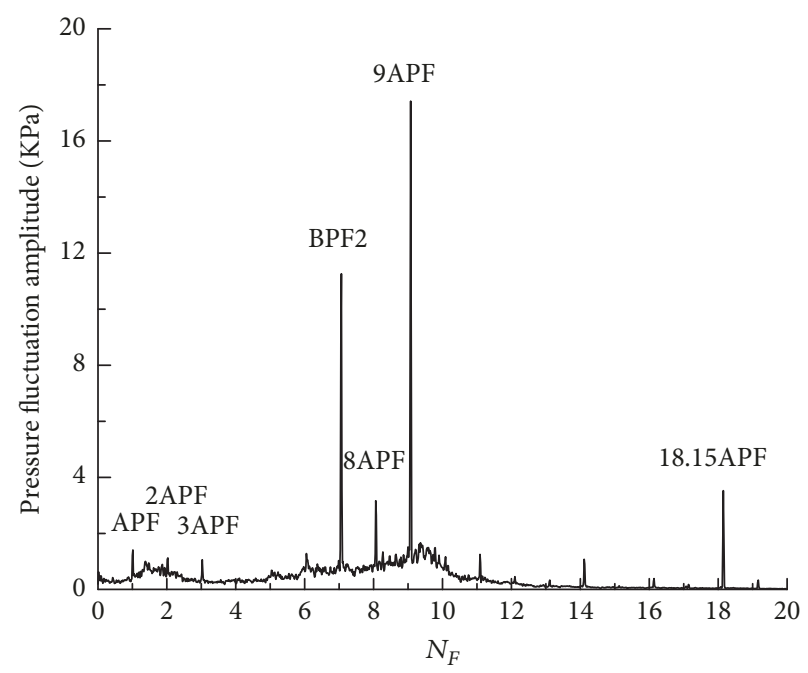

(b) P2

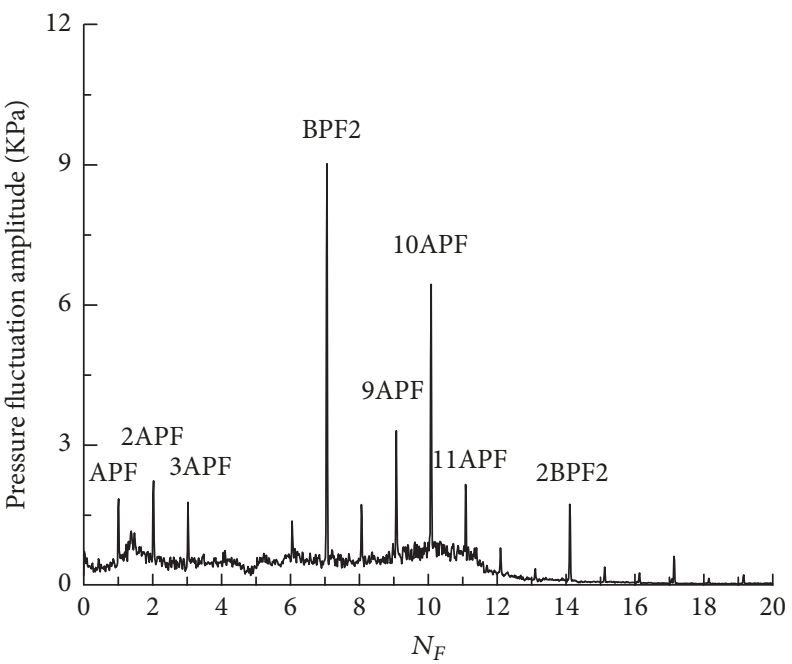

(d) $\mathrm{P} 4$

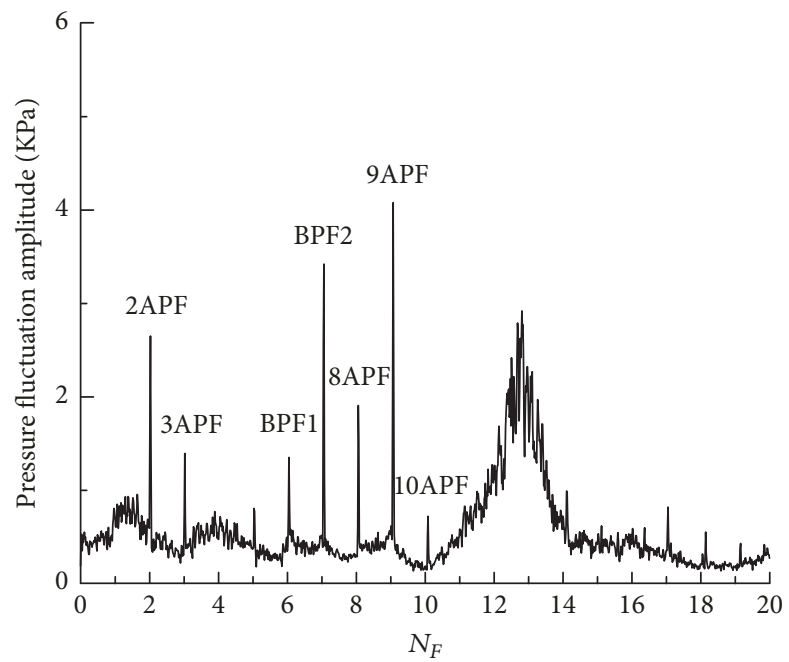

(e) $\mathrm{P} 5$

FIGURE 6: Spectrogram of pressure fluctuation under design flow rate. 


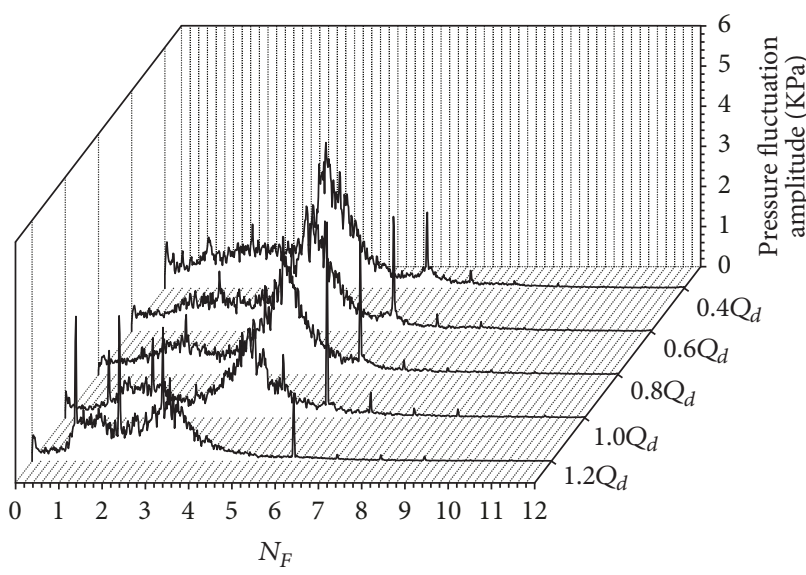

(a) P1

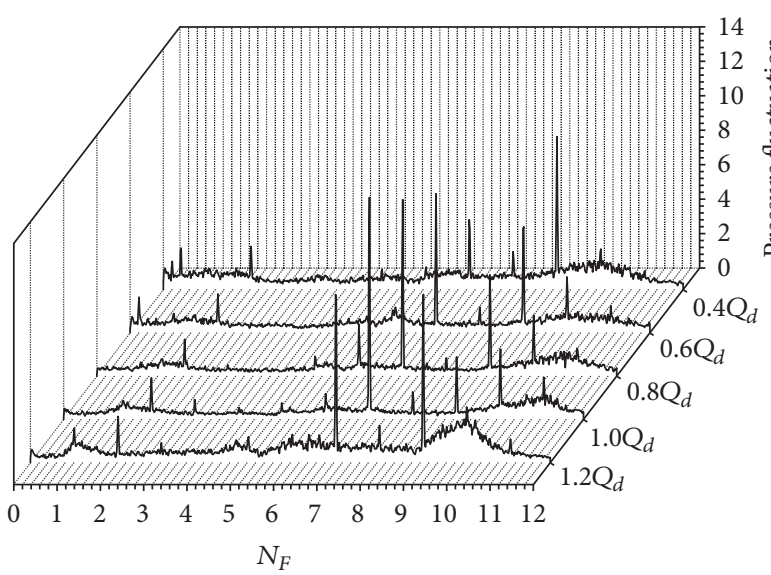

(c) P3

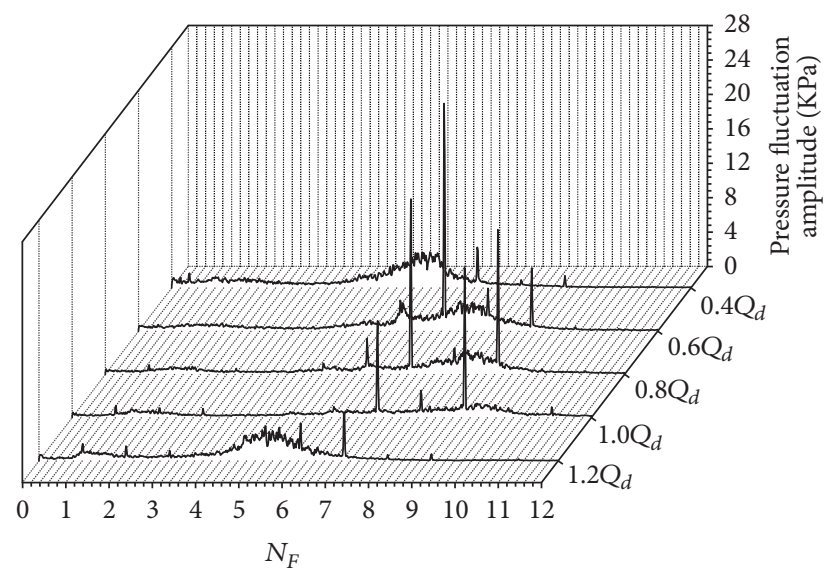

(b) P2
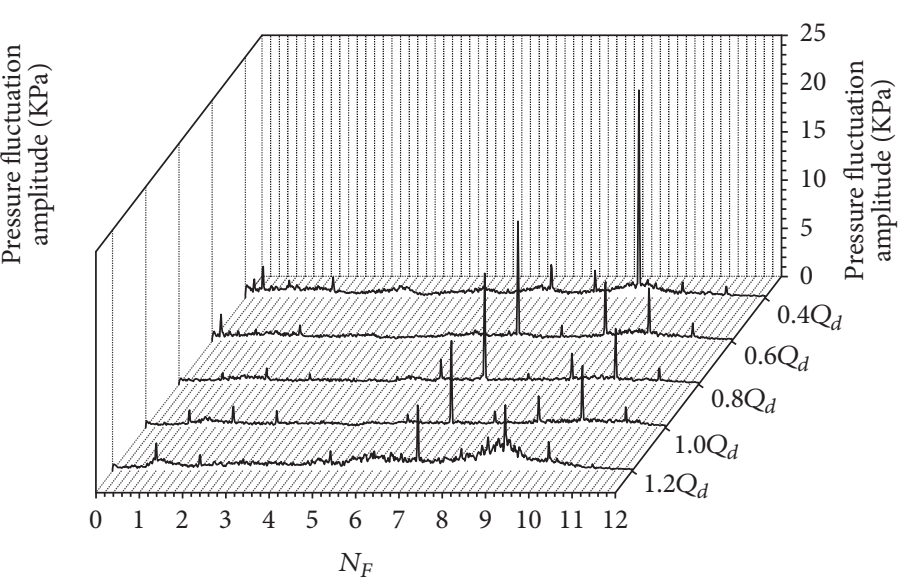

(d) P4

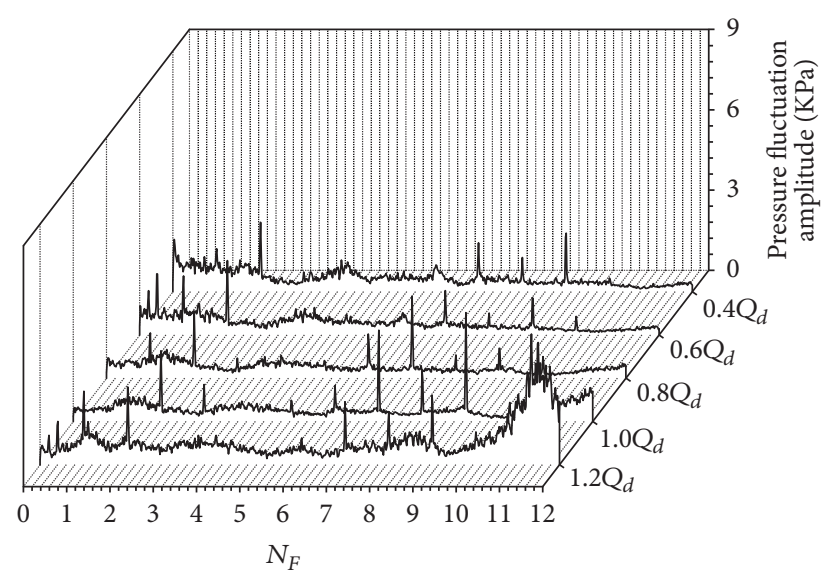

(e) P5

FIGURE 7: Pressure fluctuation spectrogram of each monitoring point.

of blade frequency increases firstly and then decreases with the increase of flow rate, and the maximum value appears at $0.6 Q_{d}$, which is $27 \mathrm{KPa}$. Under different flow rates, the fluctuation intensities of $\mathrm{P} 3$ are overall low and the difference between them is small. The dominant frequency is $9 \mathrm{APF}$ and the peak value is $8.6 \mathrm{KPa}$ under $0.4 Q_{d}$. From $0.6 Q_{d}$ to $1.2 Q_{d}$, the dominant frequency is the blade passing frequency. The general trend of peak value of the blade frequency was firstly increased, then decreased, and reached the maximum at $1.0 Q_{d}$, which was $12.6 \mathrm{KPa}$. The dominant frequency of P4 under $0.4 Q_{d}$ is $9 \mathrm{APF}$ and the peak value is relatively larger, which was $22 \mathrm{KPa}$. The dominant frequencies under other flow rate are all blade frequency. The relatively obvious characteristic frequency also includes 10APF. 


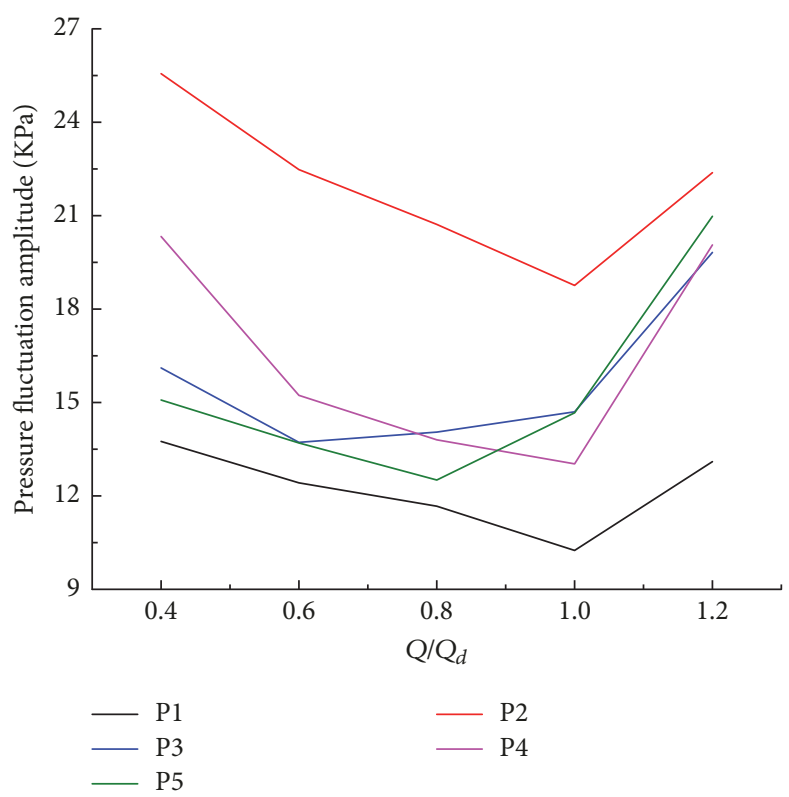

FIGURE 8: Pressure fluctuation amplitude of each monitoring point.

Figure $7(\mathrm{e})$ is the frequency domain of pressure fluctuation of monitoring point P5 at outlet of the pump. The relatively obvious characteristic frequencies are APF, $2 \mathrm{APF}, \mathrm{BPF}_{2}$, and $9 \mathrm{APF}$. The dominant frequencies under the five flow rates are $2 \mathrm{APF}, 2 \mathrm{APF}, \mathrm{BPA}_{2}, 9 \mathrm{APF}$, and $2 \mathrm{APF}$. The characteristic peak values of dominant frequencies are 2.6 KPa, 2.8 KPa, 3.1 KPa, $4.1 \mathrm{KPa}$, and 2.9 KPa. The maximum characteristic peak value appears in 9APF under design flow rate. Comparing the pressure fluctuation of P5 with the pressure fluctuation of $\mathrm{P} 1 \sim \mathrm{P} 4$, it can be found that the intensity of pressure fluctuation at the outlet is significantly smaller than that in the middle section of each stage.

3.4. Pressure Fluctuation Amplitude Analysis. The formula of pressure fluctuation amplitude is as follows:

$$
\begin{aligned}
A_{p} & =\sqrt{\frac{\sum_{i=1}^{N}(p(i)-\bar{p})}{N}} \\
\bar{p} & =\frac{1}{N \sum_{i=1}^{N} p(i)},
\end{aligned}
$$

where $p(i)$ is transient pressure value in the time domain and $\bar{p}$ is the average pressure value.

Calculating the root mean square value of the each monitoring data of the first 10 seconds, the amplitudes of each monitoring point are obtained, as shown in Figure 8. As can be seen from Figure 8, the maximum value of the fluctuation appeared at $\mathrm{P} 2$ under $0.4 \mathrm{Q}_{d}$, which was $25.56 \mathrm{KPa}$. The minimum value of the fluctuation appeared at $\mathrm{P} 1$ under $1.0 Q_{d}$, which was $10.25 \mathrm{KPa}$. The fluctuation amplitude of $\mathrm{P} 2$ is obviously higher than that of other monitoring points. This is due to the different blade numbers of first-stage impeller and second-stage impeller. The water flows through the firststage impeller and produces a characteristic frequency of
6APF. The characteristic frequency and the characteristic frequency of 7APF caused by the second-stage impeller interfere with each other, which make the flow chaotic and the fluctuating amplitude high. The values of P3, P4, and P5 are close to each other and the fluctuation amplitude of the monitoring point $\mathrm{P} 1$ is the smallest. The lowest values of $\mathrm{P} 1$, $\mathrm{P} 2$, and $\mathrm{P} 4$ are all under $1.0 \mathrm{Q}_{d}$.

\section{Test Results and Analysis of Vibration}

The test data of each monitoring point were measured two times to ensure the accuracy. During the test, the pump rotation rate is kept constant. The sampling frequency of each monitoring point is set to be $12.8 \mathrm{k}$ and the sampling time is $30 \mathrm{~s}$. The time domain signal of vibration acceleration speed is converted into frequency domain signal by Fast Fourier Transform. For the reduced leakage spectrum in conversion process, window type is adopted to be Hanning window. Acceleration signal analysis spectral range is 10 to $12800 \mathrm{~Hz}$.

4.1. Vibration Data Processing Method. Based on definition of sound pressure level, vibration acceleration speed level $L_{a}$ is defined (unit is $\mathrm{dB}$ ):

$$
L_{a}=20 \lg \frac{a_{e}}{a_{0}}
$$

where $a_{e}$ is the effective value of vibration acceleration speed, $a_{0}$ is the reference value, and $a_{0}$ usually is taken to be $10^{-6} \mathrm{~m} / \mathrm{s}^{2}$.

4.2. Characteristic Frequency Analysis of Vibration Acceleration Speed under Design Flow Rate. In order to obtain the characteristic frequency of vibration acceleration speed, the vibration acceleration spectrums of different monitoring points under design flow rate are analyzed. Figure 9 shows 
TABLE 2: Vibration acceleration in different monitoring point (dB).

\begin{tabular}{lccc}
\hline Monitoring point & Horizontal & Vertical & Axial \\
\hline V1 & 127.88 & 128.12 & 118.85 \\
V2 & 131.08 & 128.01 & 116.18 \\
V3 & 119.26 & 118.45 & 121.09 \\
V4 & 121.55 & 119.23 & 131.38 \\
V5 & 114.72 & 113.91 & 113.16 \\
V6 & 115.44 & 114.54 & 113.07 \\
V7 & 115.12 & 115.03 & 113.81 \\
V8 & 114.53 & 113.45 & 113.69 \\
\hline
\end{tabular}

the vibration acceleration speed spectrums of the eight monitoring points. $X, Y, Z$ represent the horizontal, vertical, and axial vibration acceleration speed.

It can be seen from Figure 9 that the characteristic frequencies of vibration acceleration speed of each monitoring point are basically the same. The impeller rotation rate $n$ is $1480 \mathrm{r} / \mathrm{min}$. The blade number of first-stage impeller is 6 . The blade number of second-stage impeller is 7. Then the pump shaft rotation frequency (APF) is $24.67 \mathrm{~Hz}$. The blade passing frequency of first-stage impeller is $6 \mathrm{APF}\left(\mathrm{BPF}_{1}\right)$. The blade passing frequency of second-stage impeller is 7APF $\left(\mathrm{BPF}_{2}\right)$. The main characteristic frequencies include $4 \mathrm{APF}, \mathrm{BPF}_{2}$, $9 \mathrm{APF}, 2 \mathrm{BPF}_{2}, 3 \mathrm{BPF}_{1}, 4 \mathrm{BPF}_{1}$, and $4 \mathrm{BPF}_{2}$. $4 \mathrm{APF}$ is 4 times shaft frequency. $\mathrm{BPF}_{1}$ and $\mathrm{BPF}_{2}$ are the vibration frequencies caused by the periodic interaction between blade and guide vane. $3 \mathrm{BPF}_{1}, 4 \mathrm{BPF}$, and $2 \mathrm{BPF}_{2}$ are higher harmonics of blade frequencies. The characteristic frequency of vibration at the outlet flange is obviously more than that of the inlet flange.

The above characteristic frequencies show that the blade frequency and its higher harmonics are the main source of excitation. It is an effective method to reduce the vibration of the pump by optimizing the structure and internal flow of the pump and reducing the pressure fluctuation caused by the mutual interference between impeller and guide vane. There are no obvious shaft frequency and 2 times shaft frequency on the vibration frequency spectrum. This is due to the high manufacturing accuracy of the impeller. The dynamic balance is relatively good and the coaxiality of pump shaft and motor shaft is relatively high. The excitation that can produce shaft frequency and 2 times shaft frequency is relatively small.

Table 2 shows the vibration acceleration speed levels of each monitoring point under the design flow rate. In this paper, the vibration of frequency below $1000 \mathrm{~Hz}$ is defined as low frequency vibration and the vibration frequency higher than $1000 \mathrm{~Hz}$ is defined as high frequency vibration. Low frequency vibration usually comes from the vibration of the pump. High frequency vibration usually comes from the vibration of the motor. As can be seen from Table 2, the vibration of the monitoring points V1 and V2 in the horizontal and vertical direction is greater than the axial vibration. This is because the V1 and V2 are located at the bearing. The bearings can bear the radial force and axial force generated by the rotor running. Radial force is generally larger and cyclical changes, which is related to the blade frequency. Axial force, due to function of the balance disc, is generally small and has no obvious change cycle. The vibration of V4 is greater than that of V3. This is because the inlet flow is more stable and the vibration is less. The flow in the outlet is affected by the static and dynamic interference between the impeller and the guide vane. The pressure fluctuation is more obvious. The excitation of the fluid makes the vibration of the outlet flange larger. At the same time, the vibration of the outlet flange is larger than that of the inlet flange, causing axial vibration of $\mathrm{V} 1$ at bearing A near outlet flange to be larger than that of V2 at bearing B near inlet flange.

4.3. Comparative Analysis of the Total Pump Vibration Level under Different Flow Rate. In order to further study the variation law of the pump vibration acceleration speed, the low frequency, high frequency, and total vibration level of the vibration acceleration speed level in the vertical direction of four monitoring points V5 V8 located on the pump foots are analyzed (shown in Figure 10).

It is can be seen from Figure 10 that, with the increase of the flow rate, the high frequency and the total vibration acceleration speed level increase gradually. This is because the high frequencies of vibration in the multistage pump group mainly come from the motor. The low frequencies of vibration mainly come from the pump. The amplitude of high frequency vibration is larger and it has the largest contribution to the total vibration level of the pump group. When the flow rate changes from $40 \mathrm{~m}^{3} / \mathrm{h}$ to $100 \mathrm{~m}^{3} / \mathrm{h}$, the low frequency vibration acceleration speed level decreases.

The vibration acceleration speed level of the pump is lowest under the design flow rate. It can be concluded from the low frequency vibration that the vibration acceleration speed level of the pump will be increased, when deviated from the design flow rate. When the flow rate increases from $100 \mathrm{~m}^{3} / \mathrm{h}$ to $120 \mathrm{~m}^{3} / \mathrm{h}$, the vibration acceleration speed level increases by $7.94 \mathrm{~dB}$. When the flow decreases from $100 \mathrm{~m}^{3} / \mathrm{h}$ to $40 \mathrm{~m}^{3} / \mathrm{h}$, the vibration acceleration speed level increases by only $2.51 \mathrm{~dB}$.

4.4. Vibration Intensity Analysis. The vibration intensity is the root mean square (effective speed value) of the vibration velocity under the wide frequency $(10 \sim 1000 \mathrm{~Hz})$. According to the evaluation criteria of the vibration standard, the vibration intensity of the two bearings (i.e., monitoring points $\mathrm{V} 1$ and V2) under the $40 \mathrm{~m}^{3} / \mathrm{h}, 100 \mathrm{~m}^{3} / \mathrm{h}$, and $120 \mathrm{~m}^{3} / \mathrm{h}$ are calculated, as shown in Table 3. The center height of the pump is $290 \mathrm{~mm}$ and the rotation rate is $1480 \mathrm{r} / \mathrm{min}$. As can be seen from Table 3, the maximum vibration intensity appears in the $Y$ direction of the bearing $\mathrm{B}$ under $1.2 Q_{d}$ and the vibration intensity value is $1.08 \mathrm{~mm} / \mathrm{s}$.

\section{Test Results and Analysis of Noise}

Measurement of noise is simultaneous with measurement of vibration. The sampling frequency is set as $25.6 \mathrm{k}$. The sampling time is $40 \mathrm{~s}$. The time domain signal of vibration acceleration speed is converted into frequency domain signal by Fast Fourier Transform. For the reduced leakage spectrum in conversion process, window type is adopted to be Hanning window. Noise signal analysis spectral range is 0 to $25600 \mathrm{~Hz}$. 


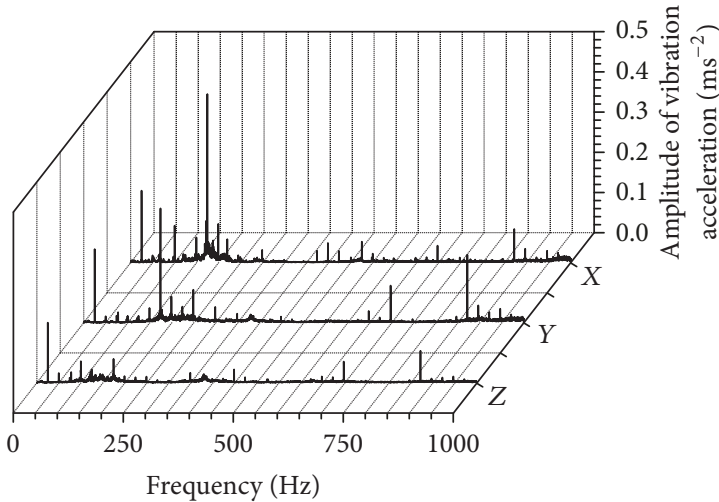

(a) V1

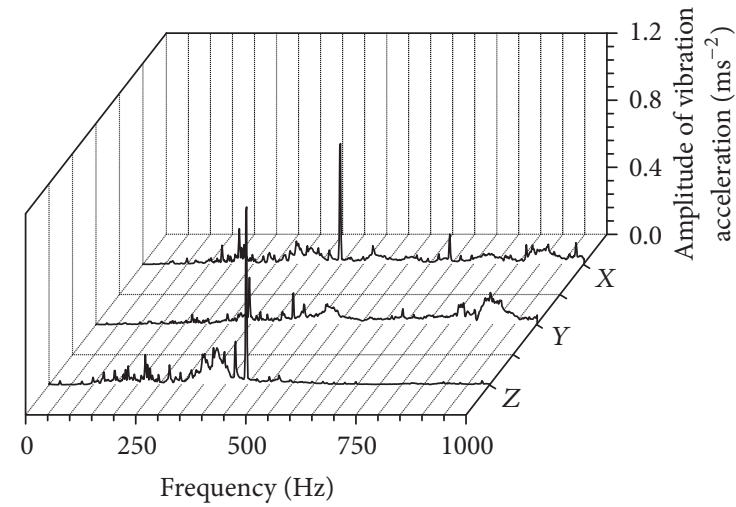

(c) V3

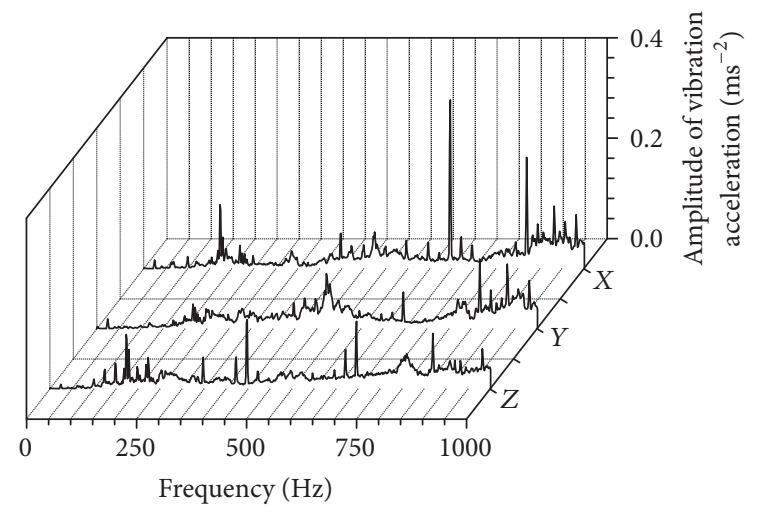

(e) V5

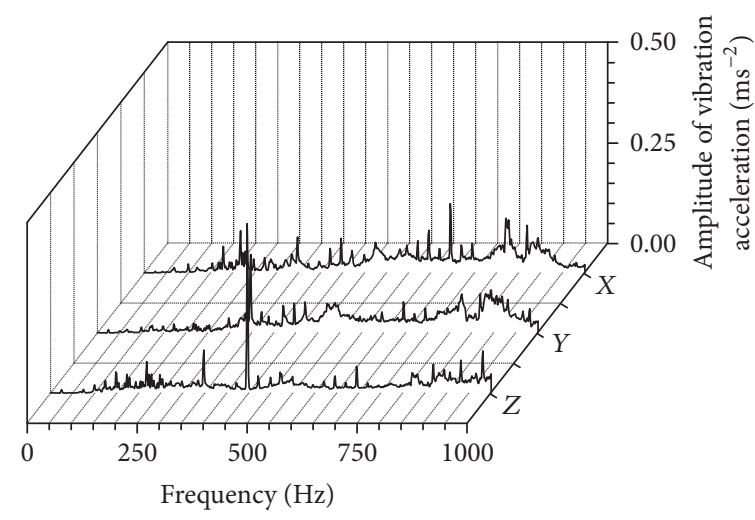

(g) V7

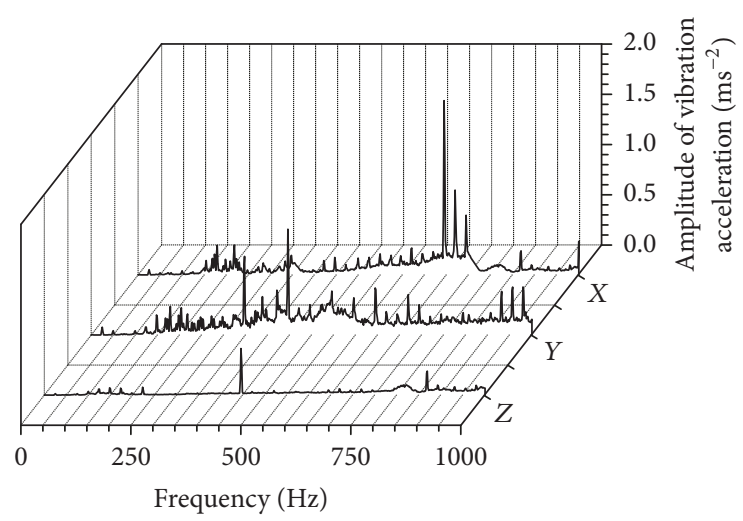

(b) V2

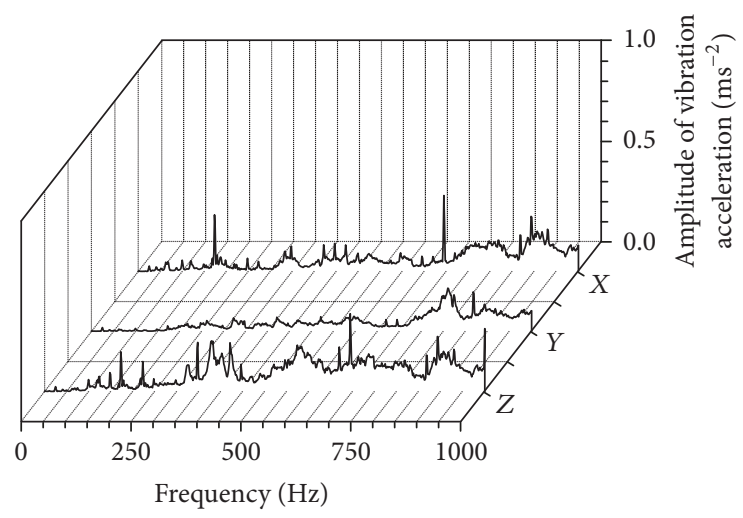

(d) V4

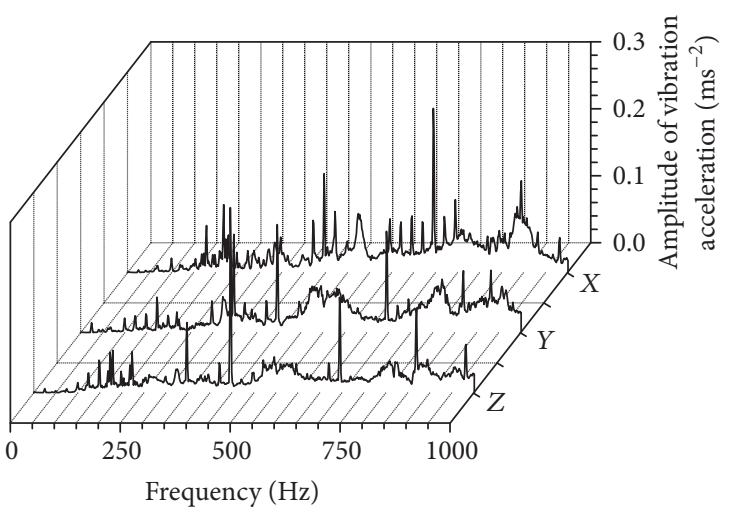

(f) V6

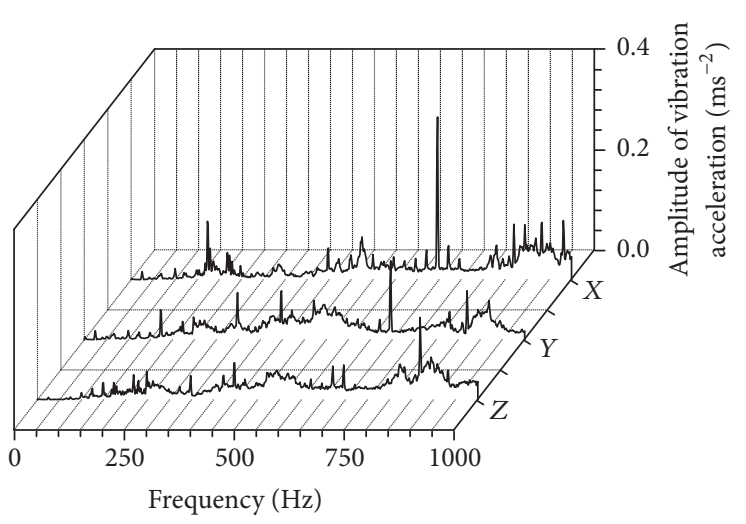

(h) V8

FIGURE 9: Spectrogram of vibration acceleration speed. 


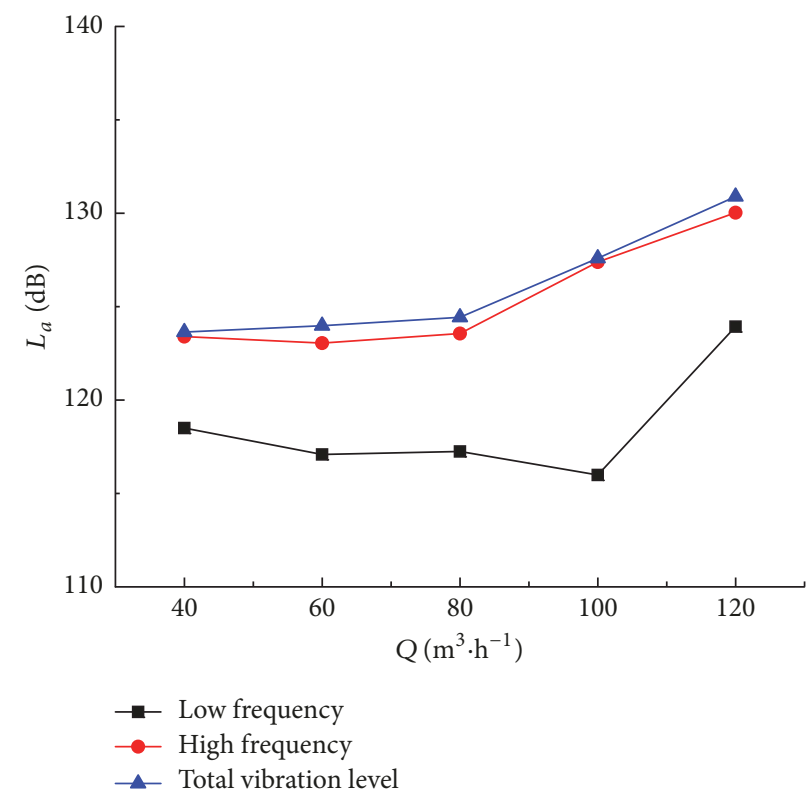

FIGURE 10: Vibration acceleration in different flow rate.

TABLE 3: Vibration intensity $(\mathrm{mm} / \mathrm{s})$.

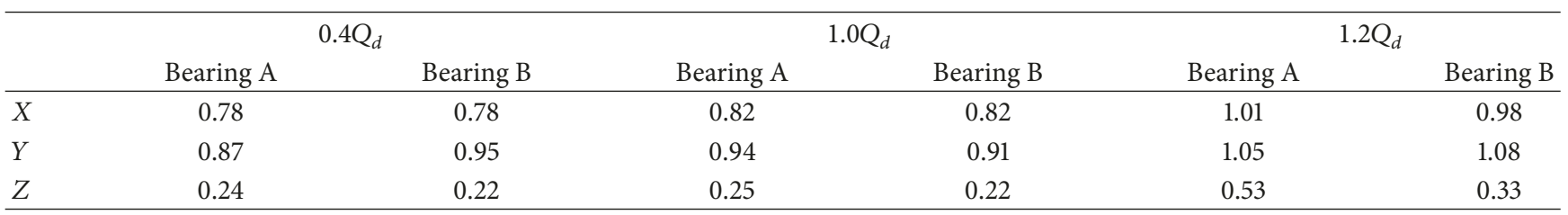

The sound pressure level (root mean square acceleration) is adopted to evaluate the noise level. The calculation formula of sound pressure level is as follows:

$$
L_{p}=20 \lg \frac{p}{p_{0}},
$$

where $p$ is the effective value of sound pressure, $p_{0}$ is the reference sound pressure, and $p_{0}$ in the air is $20 \mu \mathrm{Pa}$.

Figure 11 shows the sound pressure level of eight monitoring points under different flow rate. As seen from Figure 11, the noise level of the monitoring point can be roughly divided into three grades. The noise levels of M1, M2, and M8 near the motor are relatively higher. The noise levels of M3 and M7 at pump side are secondary. The noise levels of M4, M5, and M6 are the minimum. Thus, the noise generated by the motor accounted for the most noise of the pump group. The closer the motor to monitoring point is, the higher the noise level is. At the same time, the noise levels of the monitoring points with axis symmetric distribution are very close, such as M3 and M7, M4, and M6. When the flow rate is $40 \mathrm{~m}^{3} / \mathrm{h}$, the noise level of M2 is the highest and the noise level of M6 is the lowest. Difference in noise level is $7.7 \mathrm{~dB}$. With the increase of the flow rate, the difference between the noise levels of the monitoring points is getting smaller and smaller. When the flow rate is $120 \mathrm{~m}^{3} / \mathrm{h}$, the highest noise level of M2 is $83.6 \mathrm{~dB}$ and the lowest noise level of M6 is $81.9 \mathrm{~dB}$. The difference in noise level is only $1.7 \mathrm{~dB}$.
With the increase of flow rate, the sound pressure levels of M3 to M7 increase. However, M1, M2 and M8 had no obvious regularity. The noise change of the monitoring points shows that the noise of the pump will increase with the increase of the flow rate. When the flow rate is $120 \mathrm{~m}^{3} / \mathrm{h}$, the noise level is obviously higher than other flow rates.

\section{Conclusion}

(1) The pressure fluctuation dominant frequencies of P1 to $\mathrm{P} 5$, respectively, are $\mathrm{BPF}_{1}, 9 \mathrm{APF}, \mathrm{BPF}_{2}, \mathrm{BPF}_{2}$, and 9APF. The corresponding peak values are $4.91 \mathrm{KPa}, 17.83 \mathrm{KPa}, 13.75 \mathrm{KPa}$, $9.17 \mathrm{KPa}$, and $4.35 \mathrm{KPa}$. From the monitoring point $\mathrm{P} 1$ to the monitoring point $\mathrm{P} 5$, the intensity of the fluctuation increases firstly and then decreases.

(2) The 6 times shaft frequency caused by first-stage impeller and the 7 times shaft frequency caused by secondstage impeller produce interference. The flow is chaotic, which makes the pressure fluctuation intensity of P2 significantly higher than that of other monitoring points. Under the large flow rate and small flow rate, the fluctuation intensity increases significantly. The minimum amplitudes of the P1, $\mathrm{P} 2$, and $\mathrm{P} 4$ are under $1.0 \mathrm{Q}_{d}$.

(3) The main characteristic vibration frequencies of the pump include $4 \mathrm{APF}, \mathrm{BPF}_{2}, 9 \mathrm{APF}, 2 \mathrm{BPF}_{2}, 3 \mathrm{BPF}_{1}, 4 \mathrm{BPF}_{1}$, and $4 \mathrm{BPF}_{2}$. The radial force produced by the running rotor is bigger than the axial force and has obvious periodicity, 


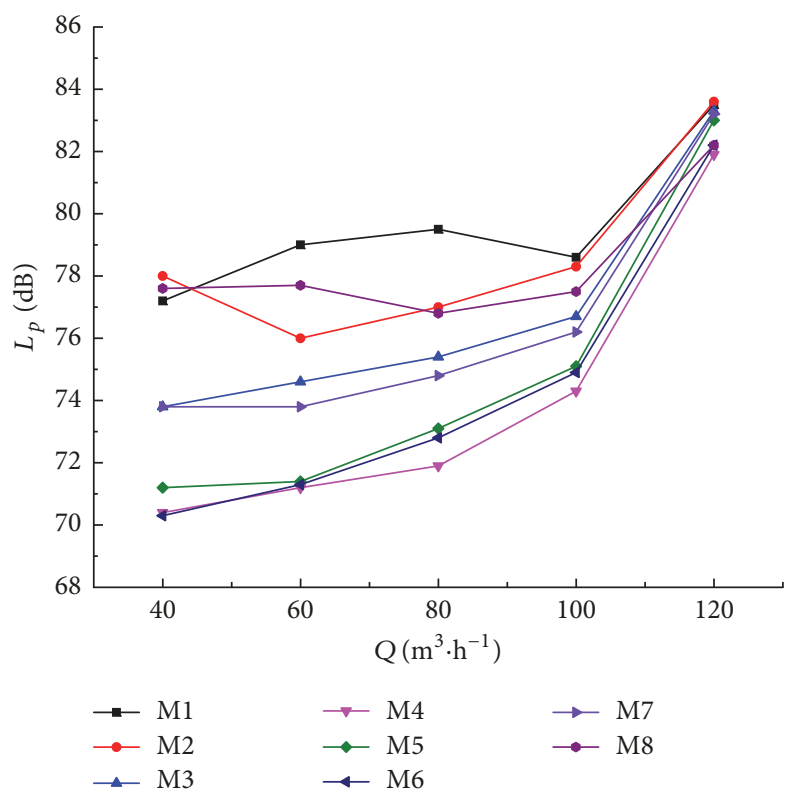

FIGURE 11: Sound pressure level under different flow rate.

which causes that the vibration intensity of the bearings in the horizontal and vertical direction is bigger than the axial vibration intensity. The maximum vibration intensity of pump bearing is $1.08 \mathrm{~mm} / \mathrm{s}$.

(4) The noise generated by the motor accounted for the most of that of the pump group. With the increase of the flow rate, the difference between the noise levels of the monitoring points is getting smaller and smaller. When the flow rate is $40 \mathrm{~m}^{3} / \mathrm{h}$, the maximum difference of noise level of each monitoring point is $7.7 \mathrm{~dB}$. When the flow rate is $120 \mathrm{~m}^{3} / \mathrm{h}$, the maximum difference of noise level of each monitoring point is only $1.7 \mathrm{~dB}$.

\section{Conflicts of Interest}

The authors declare that they have no conflicts of interest.

\section{Acknowledgments}

The authors gratefully acknowledge the support from the National Key Research and Development Program of China (Grant no. 2016YFB0200901), the National Natural Science Foundation of China (Grant no. 51679110), and Priority Academic Program Development of Jiangsu Higher Education Institutions (PAPD).

\section{References}

[1] Y. Li, W. Shi, and X. Han, "Effects of pump hydraulic structure on vibration characteristics of series-parallel centrifugal pump," Paiguan Jixie Gongcheng Xuebao/Journal of Drainage and Irrigation Machinery Engineering, vol. 33, no. 9, pp. 744-749, 2015.

[2] A. Lucius and G. Brenner, "Numerical simulation and evaluation of velocity fluctuations during rotating stall of a centrifugal pump," Journal of Fluids Engineering, vol. 133, no. 8, Article ID 081102, 2011.
[3] S. Guo and M. Yoshiyuki, "Experimental investigations on pressure fluctuations and vibration of the impeller in a centrifugal pump with vaned diffusers," International Journal B, vol. 48, no. 1, pp. 136-143, 2005.

[4] M. W. Trethewey, J. C. Friell, M. Jeya Chandra, and M. S. Lebold, "A spectral simulation approach to evaluate probabilistic measurement precision of a reactor coolant pump torsional vibration shaft crack monitoring system," Journal of Sound and Vibration, vol. 310, no. 4-5, pp. 1036-1056, 2008.

[5] J. Feng, F.-K. Benra, and H. J. Dohmen, "Investigation of periodically unsteady flow in a radial pump by CFD simulations and LDV measurements," Journal of Turbomachinery, vol. 133, no. 1, Article ID 011004, pp. 1-4, 2011.

[6] Y. Wang, S. Yuan, J. Zhang, J. Mao, and X. Huang, "Pressure fluctuation characteristics of centrifugal pump with low-specific speed at low flow rate," Paiguan Jixie Gongcheng Xuebao/Journal of Drainage and Irrigation Machinery Engineering, vol. 34, no. 5, pp. 399-405, 2016.

[7] R. X. Perez, R. A. Akins, C. E. Lee, and H. F. Taylor, "Fiber-optic pressure sensors detect cavitation and flow instabilities in centrifugal pumps," World Pumps, no. 359, pp. 28-33, 1996.

[8] N. Takahiro and O. Yusuke, "Pressure fluctuation in a vaned diffuser downstream from a centrifugal pump impeller," International Journal of Rotating Machinery, vol. 621, no. 9, pp. 285292, 2003.

[9] R. Spence and J. Amaral-Teixeira, "Investigation into pressure pulsations in a centrifugal pump using numerical methods supported by industrial tests," Computers \& Fluids, vol. 37, no. 6, pp. 690-704, 2008.

[10] R. Spence and J. Amaral-Teixeira, "A CFD parametric study of geometrical variations on the pressure pulsations and performance characteristics of a centrifugal pump," Computers \& Fluids, vol. 38, no. 6, pp. 1243-1257, 2009.

[11] K. Majidi, "Numerical study of unsteady flow in a centrifugal pump," Journal of Turbomachinery, vol. 127, no. 2, pp. 363-371, 2005. 
[12] G. Kergourlay, M. Younsi, F. Bakir, and R. Rey, "Influence of splitter blades on the flow field of a centrifugal pump: test-analysis comparison," International Journal of Rotating Machinery, vol. 2007, Article ID 85024, 2007.

[13] H. Dai, H. Liu, J. Ding, M. Tan, and Y. Wang, "Effects of impeller outlet width on pressure pulsation in two side chambers of centrifugal pump," Paiguan Jixie Gongcheng Xuebao/Journal of Drainage and Irrigation Machinery Engineering, vol. 33, no. 1, pp. 20-25, 2015.

[14] H. Liu, X. Zhou, K. Wang, and L. Mao, "Analysis on pressure fluctuation of radial diffusers in a multistage centrifugal pump," Zhongnan Daxue Xuebao (Ziran Kexue Ban)/Journal of Central South University (Science and Technology), vol. 45, no. 9, pp. 3295-3300, 2014.

[15] M. S. Howe, "On the estimation of sound produced by complex fluid-structure interactions, with application to a vortex interacting with a shrouded rotor," Proceedings of the Royal Society A Mathematical, Physical and Engineering Sciences, vol. 433, no. 1889, pp. 573-598, 1991.

[16] J. Choi, D. K. McLaughlin, and D. E. Thompson, "Experiments on the unsteady flow field and noise generation in a centrifugal pump impeller," Journal of Sound and Vibration, vol. 263, no. 3 , pp. 493-514, 2003.

[17] O. P. Srivastav, K. R. Pandu, and K. Gupta, "Effect of radial gap between impeller and diffuser on vibration and noise in a centrifugal pump," Journal of the Institution of Engineers (India): Mechanical Engineering Division, vol. 84, no. 1, pp. 36-39, 2003.

[18] C. Dai, L. Dong, F. Kong, Z. Feng, and Y. Bai, "Mechanism analysis of vibration and noise for centrifugal pump working as turbine," Nongye Gongcheng Xuebao, vol. 30, no. 15, pp. 114-119, 2014.

[19] L. Sun, J. Xie, J. Shang, and D. Zhang, "Experimental study on noise and vibration characteristics of variable speed circulator pump," Fluid Machinery, vol. 42, no. 10, pp. 6-10, 2014.

[20] L. Zhou, "Analysis on pressure fluctuation and vibration of a centrifugal pump for off-design conditions," Fluid Machinery, vol. 43, no. 2, pp. 52-55, 2015.

[21] X. Duan, Y. Wang, and Y. Su, "Vibration analysis applied in cavitation monitoring of a centrifugal pump," Journal of Vibration and Shock, vol. 30, no. 4, pp. 161-165, 2011 (Chinese).

[22] X. Escaler, E. Egusquiza, M. Farhat, F. Avellan, and M. Coussirat, "Detection of cavitation in hydraulic turbines," Mechanical Systems and Signal Processing, vol. 20, no. 4, pp. 983-1007, 2006. 


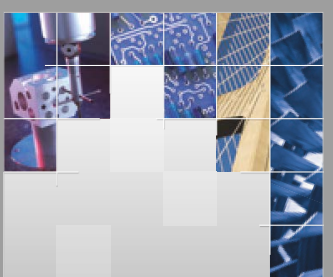

\section{Enfincering}
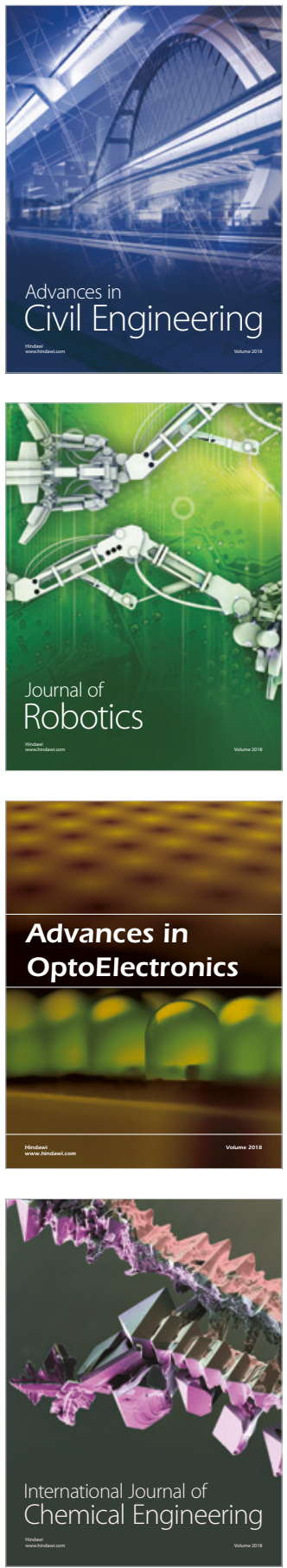

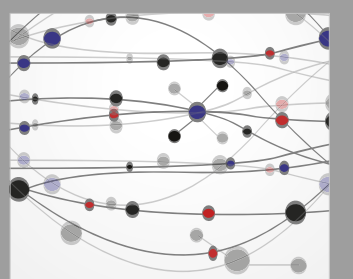

\section{Rotating \\ Machinery}

The Scientific World Journal

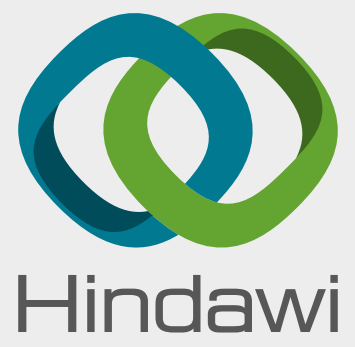

Submit your manuscripts at

www.hindawi.com
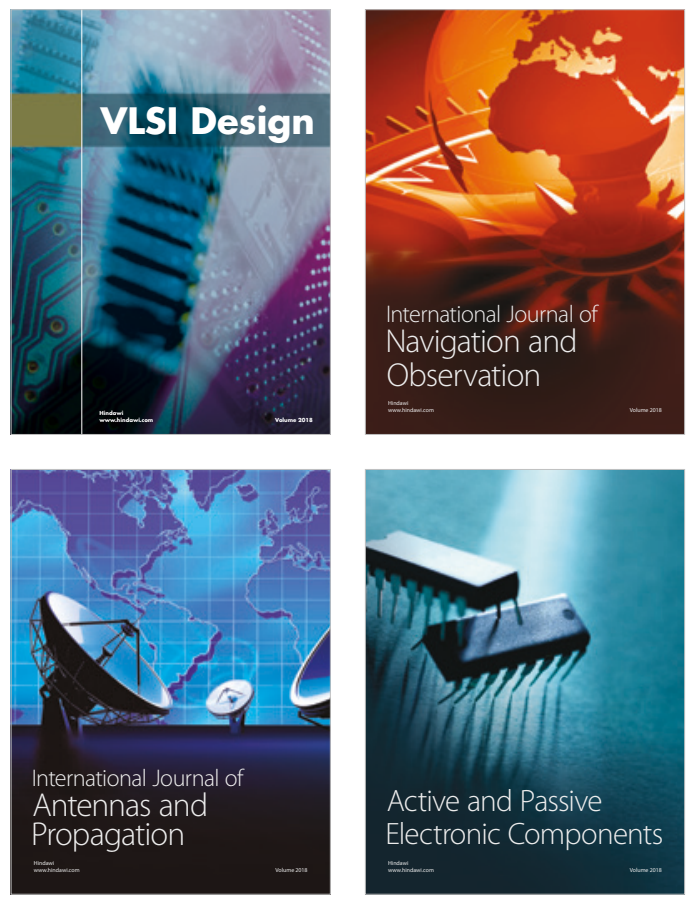
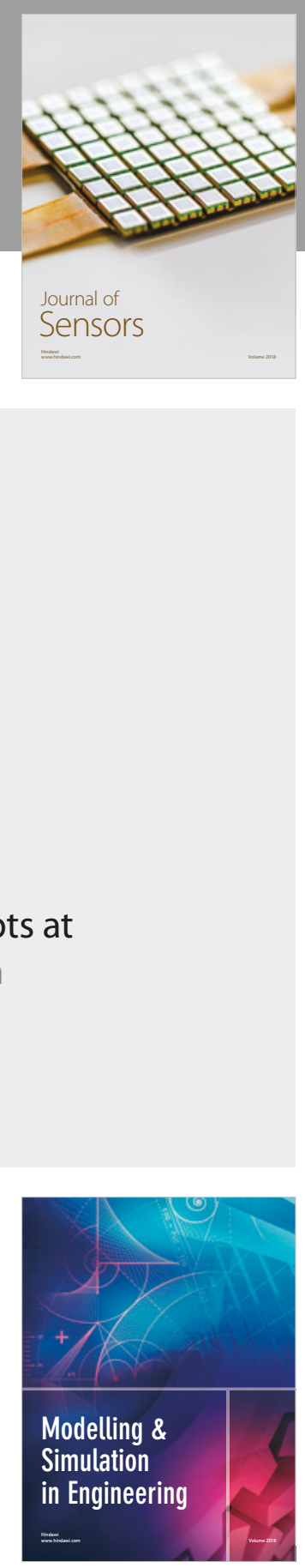

\section{Advances \\ Multimedia}
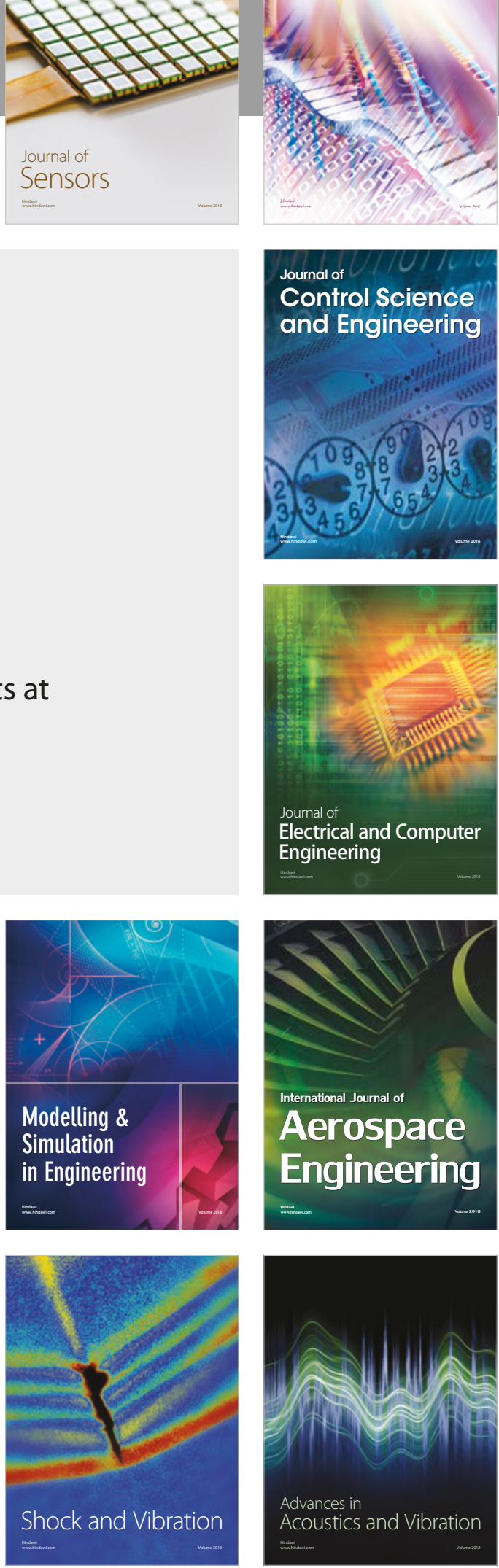